\title{
Equity, environmentalism, and conscious consumerism: A review of Grocery Activism
}

Review by Leah Halliday, University of Louisville*

Review of Grocery Activism: The Radical History of Food Cooperatives in Minnesota, by Craig B. Upright. (2020). University of Minnesota Press. Available as paperback; 264 pages. Publisher's website: https://www.upress.umn.edu/book-division/books/grocery-activism

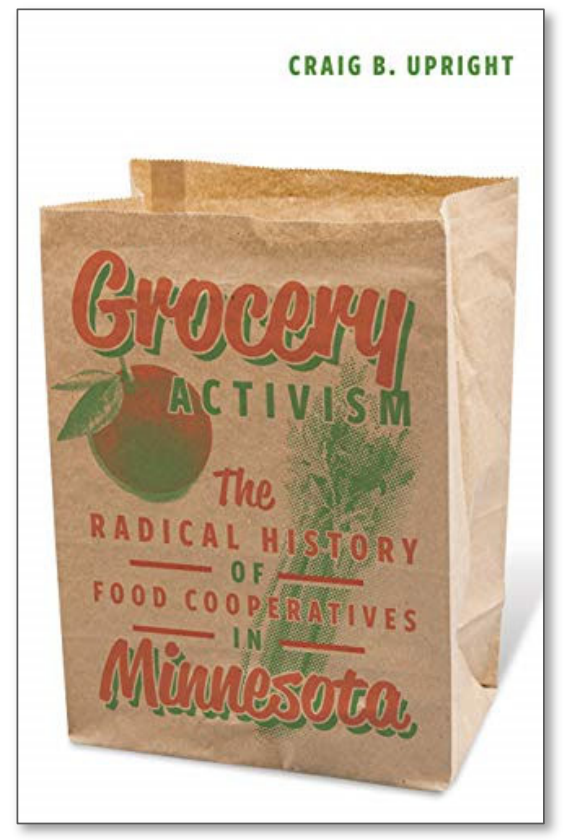

Submitted June 15, 2020 / Published online August 4, 2020

Citation: Halliday, L. (2020). Equity, environmentalism, and conscious consumerism:

A review of Grocery Activism [Book review]. Journal of Agriculture, Food Systems, and

Community Development, 9(4), 335-337. https://doi.org/10.5304/jafscd.2020.094.024

Copyright $(2020$ by the Author. Published by the Lyson Center for Civic Agriculture and Food Systems. Open access under CC-BY license.

$\mathrm{T}$ wo crises pervading the current consciousness of society-the COVID-19 health crisis and the ongoing crisis of police brutality against Black Americans as evident in the recent murder of George Floyd in Minneapolis-make Craig B. Upright's Grocery Activism: The Radical History of Food Cooperatives in Minnesota particularly timely and relevant, though neither is the direct topic of the book. Upright outlines how grocery co-ops were able to find, sustain, and promote a niche in the market through a symbiotic relationship with the

* Leah Halliday is a doctoral candidate at the University of Louisville, Kentucky. Her research interests include the influences of culture and community on teaching and learning. She can be contacted at lmhall04@louisville.edu natural and organic foods movement. Readers encounter a variety of voices from Minnesota's rich history of food co-ops, and while some voices are notably missing, the book provides a foothold into exploring the broad environmental, social, and economic implications of the aphorism Upright notes in the text: "Food is power."

Some tout the COVID-19 health crisis as a foreshadowing of the as yet unimagined manifestations of industrialized societies' failed stewardship of the earth. Upright's exploration of the connected development of the organic farming and grocery cooperative movements provides a thoughtful perspective on the power of food-based activism to influence values and foster a sense of conscious consumerism. One method for the latter 
is through the power of what Upright refers to as the "buycott," a low-risk way to engage and sustain a sense of involvement with a movement through purposeful spending. Upright transports readers accustomed to organic choices even in mainstream stores to a time when these items were not only not available, but when the language and meaning of the terms had not been developed. He outlines pushback against the industrialization of agriculture through appeals to environment and personal health. His arguments focus on the organic food movement but touch on labor and land ownership by presenting the commodification of agriculture as a social and environmental harm. Upright examines the impact of retail co-ops in raising awareness and serving as stewards of information on sustainable agricultural practices. Indeed, Upright's research would contribute to any conversation on green development and challenging the industrialized agricultural practices and infrastructures on which our society relies.

In creating a context for the co-op history, in addition to the exploration of the organic food movement, Upright establishes the Twin Cities as a prime, progressive locale for the development and sustenance of new wave cooperative groceries in the 1970s and beyond. This image of the area is difficult to reconcile with the revelations of the racial and economic inequities in Minneapolis that have captured the world's attention in recent weeks. A part of this narrative that is largely missing, the stories of the Black co-ops, would help provide a fuller picture of Minnesota's co-op story. While Upright rarely focuses on individual co-ops, focusing instead on a larger picture of the movement, his representation of minimalistic 1970s coops that kept the keys to the storefront at the police station for members to pick up as needed after hours does not address who would be excluded by this sort of arrangement. Further, while Upright includes a variety of historic photographs, including some of the Credjafawn Co-op Store (a successful African-American cooperative from the early first wave of cooperatives in the state), his mention of the store's destruction when the freeway "was plotted through the center of the neighborhood" barely hints at the added complexity of the position of Black co-op organizers in this social-economic experiment in cooperation (p. 63).

Perhaps the most exciting part of Upright's history emerges in chapter 4 , where he delves into the drama that emerged in Minneapolis from 1975 to 1976. During this year, the politically focused, Marxist-leaning Cooperative Organization (CO) clashed violently with the more natural-foodsfocused contingent, forcefully occupying the area co-ops' primary distribution center, the People's Warehouse. Upright reasons that anti-war sentiment had brought many to the cooperative movement with a genuine but somewhat vague passion for change that was able to jumpstart an impressive surge of retail co-ops and a distribution infrastructure. He describes the co-op wars as a fire that forced the cooperatives to clarify the direction of their passions moving forward, allowing for more purposeful cooperation between co-ops. Those that survived were those that opted to focus on natural and organic foods. The co-op wars, Upright argues, actually strengthened the commitment and connections of the co-ops that survived; he highlights Hayagreeva Rao's concept of "hot causes" and "cool mobilization" in this convincing analysis. Still, while Upright suggests that the CO leaders' anti-imperialist stance may have been less than genuine, additional stories could help bear that conclusion out. The Bryant-Central co-op, for instance, the site of which was very near the now rapidly gentrifying area where George Floyd was killed, was a Black co-op in an area of the city where Black families were long compelled—by redlining and racial covenants in leases-to live. It is included in Upright's comprehensive catalog of area co-ops but not elsewhere in the book. The stories of the city's Black co-ops could help illuminate the complexity of the concept of cooperation between co-ops through which Upright understands the co-op wars.

The final chapter and conclusion look at the present and future. Considering the success of coops at making organic food so desirable and widely accessible an option, Upright acknowledges, one might expect co-ops to become obsolete. However, they are still driven by more than a financial bottom line. As arbiters of causes and conscious consumerism, co-ops will likely continue to define and develop their own relevance, just as they devel- 
oped their business practices. Co-ops are poised to pivot toward new causes, allowing members and shoppers to continue to live their values at minimal risk. Upright points to the developing focus on local foods as a possible next direction.

Ultimately, with Grocery Activism Upright provides a wealth of food for thought. He offers a bird's eye view of the intersections of the organic food movement and the dramatic history of grocery cooperatives, focused on a place where many co-ops still thrive today. While his work hits the current social landscape at just a time and in just a place that may draw readers' attention to the voices that are omitted, the text is rich in detail and insight and may serve as a springboard into further research and discussion. 